\title{
DISCURSO DE POSSE
}

\section{Laura Cavalcante Padilha*}

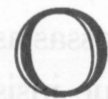

s pesquisadores brasileiros - e aqui começo por reiterar o tantas vezes já dito - vivem uma das piores crises de toda a trajetória da investigação científica no país. Sobre eles se abateu uma densa e tensa malha de negatividade e desconfiança, tecida pelos gestores da educação nacional. Estes, comprometidos com as tecnologias externas de nossos devedores, hipotecaram a nossa própria soberania, daí a urgente necessidade de tornar estéril qualquer tentativa de avanço científico e/ou tecnológico. Daí também o olhar enviesado, quase deliberadamente torto - como o do anjo cantado por Drummond - sobre o que fazemos, o que somos e o que queremos, ou seja, sobre tudo que vai de encontro ao desejo rasteiro de que a pesquisa brasileira caminhe para seu sucateamento e dispersão.

O mais difícil de aceitar é a forma inocentemente tranqüila com que os dirigentes brasileiros nos abrem as portas da subalternidade e da dependência científica, se consideramos terem sido suas algumas das vozes que, no passado, se ergueram para criar imagens solidamente utópicas sobre o sentido dessas mesmas subalternidade e dependência, fazendo-nos sonhar com a possibilidade de um futuro de reconstrução e paz social. E é por isso que, hoje, eles nos pedem para esquecer esse passado, contido no que escreveram, querendo-nos cabisbaixos, para que outros possam altivamente levantar as cabeças, sem qualquer obstáculo a lhes barrar o sonho. Em certa medida, as associações científicas, ao congregarem docentes e pesquisadores das mais diferentes áreas do conhecimento no país, se tornam espaços privilegiados para que possamos resistir, mantendo acesa

* Presidente da ANPOLL. 
PADILHA, Laura Cavalcante. Discurso de posse.

a chama que nos impele, como ensinou o poeta angolano $\Lambda$ gostinho Neto, para nosso próprio caminho das estrelas. $\Lambda$ o nos reunirmos, sob a égide desses espaços científicos aglutinadores, anual ou bianualmente, uns com os outros, publicizamos os resultados de nossas pesquisas, ao mesmo tempo em que os discutimos, sempre em mútua interação. Saímos mais fortalecidos desses encontros, o que não significa o não ter de corrigir rumos, traçando outras metas, pensando novas metodologias, enfim, redefinindo os objetivos que inicialmente nos nortearam. Por tal razão, nossas associações têm cada vez menos lugar junto ao poder público que insiste em "invisibilizá-las", criando impasses e impedindo as condições que nos conduziriam a todos a um diálogo mais sereno e profícuo.

Os nossos encontros científicos, por tudo isso e em resumo, não são vazios e/ou inócuos, como alguns nos querem fazer crer, mas uma possibilidade desejavelmente concreta de plena circulação do pensamento científico nacional que, por tal via, se fortalece, galgando mais altas posições no plano internacional. Na teoria é isso, mas a prática nos mostra que se torna cada vez mais difícil nos mantermos equilibrados no tenso arame da cultura acadêmica brasileira, quando são tantos os agentes de desequilíbrio de que estamos cercados. Vale a pena talvez aqui abrir um parêntesis para chamar um pouco a atenção para essa vida de acrobata dos docentes/ pesquisadores brasileiros que estão na vigência do pleno exercício de sua cidadania democrática, infelizmente posta em questão pelas regras do jogo da tão propalada, embora tão eivada de contradições, política neo-liberal vigente.

$\Lambda$ s agências de fomento, órgãos alavancadores da formação/qualificação dos membros do magistério superior, além de centros sustentadores da nossa pirâmide científica, melancolicamente nos acenam com o desmanchar de sua solidez, se pensamos, com Marx, que tudo que é sólido desmancha no ar. $\Lambda$ que, nesse momento, acrescentaria: ou é deliberadamente desmanchado? Para tentar, de forma apenas esquemática, responder à indagação, trago para o centro de minhas reflexões um pouco do 
Rev. $A N P() L L$, n. 6/7, p. 315-323, jan./dez. 1999

cotidiano do pesquisador brasileiro, em seu envolvimento com as agências de fomento, instituições indispensáveis ao pleno êxito de seus propósitos.

Para começar, deixando de lado a questão das bolsas de mestrado e doutorado e todo o desmantelamento sofrido pelo sistema, penso no pesquisador que, já doutor, bate à porta de uma das agências. Vejamos a questão pontual da bolsa de produtividade, na não menos pontual agência que é o CNPq, um centro da mais alta tradição na história científica nacional, que, por décadas, aprendemos a respeitar. De início, o jovem doutor (já formado há mais de dois anos, quase sempre) deve disputar um lugar, via de regra já ocupado pelos pesquisadores seniores que estão, de há muito, no sistema de fomento. No fundo da cena, a grande desconfiança que vale aqui explicitar, ou seja, a desconfiança de que a bolsa de produtividade sirva menos para dar alicerce à pesquisa do que para aumentar um salário historicamente corroído e aviltado. Nesse universo nebulosamente confuso, o projeto é apresentado, pela primeira vez, e, freqüentemente, o mérito é reconhecido, mas se responde que não há como implementar a demanda, por falta de verba. Se implementada, de outra parte, começa o que eu ouso aqui chamar de um quase pesadelo de papéis (já agora disquetes). Tento dizer porque, assumindo a responsabilidade por minha avaliação, de cunho totalmente pessoal.

Por não haver um sistema ordenado de coleta e armazenamento de informações, perdemos a conta do número de vezes que oferecemos a mesma informação, sob capas diferentes ou, melhor dizendo, com uma disposição lingüística que diz o mesmo, de outra forma. Cada novo sistema apresentado é incomunicante. Não se consegue sair de um banco de dados para outro. Tudo é fechado. Temos sempre, e por conta disso, um novo outro modelo, apresentado em outro programa, sob o disfarce de que é outro o objetivo. Relatórios e mais relatórios. Dados e mais dados. Tempo e mais tempo. E o equilibrio no arame continua.

Quanto à emissão de pareceres, o que admito faça mesmo parte de nosso papel de pesquisador, há novos complicadores. Nem sempre o as- 
PADILHA, Laura Cavalcante. Discurso de posse.

sunto a ser analisado é de nossa direta competência científica. Para dar conta do viés indesejável, valemo-nos de nossas bibliotecas particulares e não só -, quando o tempo urge, já que só temos um prazo de vinte dias, vividos, diga-se de passagem, no meio de nosso emaranhado cotidiano docente. Tudo isso nos leva a um quase desespero, além do enorme desconforto que nos causa o temor de cometer injustiça com um colega da área.

Por fim, e voltando ao que motivou o parêntesis, a questão da participação em eventos científicos, cuja importância já foi assinalada. $\Lambda$ s universidades de origem, combalidas pela pressão financeira e pelos múltiplos cortes e/ou contingenciamentos, não podem atender à demanda, sobretudo se o evento é no exterior (o que está impedido, nas federais, pela legislação vigente). $\Lambda$ s fundações locais de amparo à pesquisa, com raras exceções, não têm recursos suficientes para atender a todo o balcão, motivo por que negam mais que concedem. $\mathrm{O}$ caminho é bater à porta das agências nacionais que, dependendo do tempo cronológico em que devem fazer o desembolso, têm menos ou mais verba. Quase sempre, é menos. Como desoladora, embora apaziguante resposta, o pesquisador recebe o comunicado, nos tempos vividos hoje, tão absurdamente corriqueiro: a demanda foi aprovada no mérito, mas não há recursos financeiros para seu atendimento. E vem o cansaço, um cansaço enorme, de pernas e de braços como dizia Ńlvaro de Campos.

Temo, por tudo até aqui elencado, o amanhecer de um dia em que nos deparemos com sombrias notas em nosso computador pessoal ou na mídia (embora sem manchetes): o apoio à pesquisa no Brasil está absolutamente contingenciado e sem previsões de prazo de retorno. Nesse dia, de joelhos, a pesquisa brasileira entoará o seu réquiem. E eles quase terão ganho a luta. Quase, porque creio na resistência do arame, forte demais para partir-se. Do alto, continuaremos nossa luta, com o apoio silenciosamente expectante do público, a torcer por nós. Malabaristas, não estamos em busca dos aplausos fáceis e/ou gritos delirantes. Interessa-nos, tão so- 
mente, o respeito pela profissão por nós escolhida. Temos consciência de nosso papel e a certeza de podermos contribuir, com as ferramentas de nosso saber, para o processo de reconstrução plena de uma nação soberana, cujos dirigentes precisam, com humildade, reaprender o valor semântico da expressão justiça social, acoplando-a a outra, não menos significativa: fim dos privilégios.

Fecho o parêntesis, voltando, quase à guisa de conclusão, à questão do regime associativo no Brasil, enfocando, de forma especial, a $\Lambda$ NPOLL que, por dois anos, a equipe, ora por mim representada, dirigirá. Como já apontei, as associações científicas do país, para além de serem um foro privilegiado de circulação e consolidação do pensamento científico, representam um espaço de resistência onde se discutem não apenas os grandes problemas de cada área, mas, sobretudo, os rumos do próprio sistema educacional brasileiro, em geral, e do universitário, em particular.

No caso específico da $\Lambda$ NPOLL, ela significa, há quase uma década e meia, o lugar simbólico onde as pesquisas de Letras e Lingüística ganharam visibilidade e os cursos de pós-graduação puderam ser amplamente discutidos e, em certa medida, redimensionados. 0 sistema de avaliação montado pela CAPES teve o grande mérito de criar padrões uniformes para todas as instituiçōes. Se precários, se falíveis, se cerceadores, não é questão para ser aqui problematizada. 0 importante, a nosso ver, foi a criação de parâmetros avaliativos aos quais todos os programas igualmente se submeteram. Ora, nesse quadro, à nossa $\Lambda$ ssociação coube o papel de discutir tais modelos avaliatórios, propiciando aos cursos a ela filiados a oportunidade de análise e correção de seus próprios rumos acadêmicos e teórico-metodológicos. $\Lambda$ ssim, foram postas em discussão questões como: flexibilização de currículos, ementas e programas; linhas de pesquisa; criação de revistas para circulação do pensamento científico da área; necessidade de agilização do fluxo de alunos; parcerias inter-institucionais etc.

De outra parte, os pesquisadores reunidos nos grupos de trabalho ganharam um espaço multiplicador dos resultados de suas investigações 
PADILHA, Laura Cavalcante. Discurso de posse.

científicas. É possível medir-se a importância de certas linhas de pesquisa que dão o perfil da pós-graduação no país, por exemplo, pelo rastreamento do processo de criação e/ou fechamento de grupos, assim como pelo número de participantes de cada um deles, isso sem falar nos interesses temáticos. Há de chegar o momento de se traçar a trajetória das pesquisas em Letras e Lingüística no Brasil, de modo mais orgânico e consolidado. Nesse instante, com certeza se verá que, a partir da criação da $\Lambda$ NPOLL, se torna mais nítida a rede de inter-relações estabelecidas entre os pesquisadores brasileiros da área. Cada grupo de trabalho é um texto em si mesmo onde se entrelaçam os fios do tecido pelo qual se pode ler a nossa própria história. Memória e documento.

Vale aqui reiterar ter a $\Lambda$ NPOLL crescido, nesses 14 anos, e nós com ela. Talvez por isso, no momento em que assumimos a sua direção - e lembro os nomes dos companheiros de travessia: Teresa Cristina Cerdeira da Silva; Lúcia Teixeira de Siqueira e Oliveira; Bethânia Sampaio Corrêa Mariani; Edson Rosa da Silva e Cláudia Nívia Roncaratti de Souza -, cabe perguntar: que propósitos nos movem, nos dois anos de futura gestão? $\Lambda$ resposta se pode encontrar na plataforma apresentada no VI Congresso Nacional, realizado em Campinas, sob a presidência do colega Eduardo Guimarães, com o apoio dos outros membros da diretoria. Antes de apresentá-la, porém, gostaria de deixar claro que nossa gestão quer uma continuidade de tudo aquilo já construído pelos que nos antecederam à frente da $\Lambda$ ssociação, por nós vista como uma espécie de imenso vitral, harmonicamente planejado, onde cada nova equipe se acrescenta, criando novos desenhos, com os pedaços dos vidros de que dispõe, a cada novo momento histórico. É preciso não deixar que os vidros se partam, assegurando-se, repito, a harmonia, o jogo de cores, o tamanho de cada peça etc., sempre lembrando que um vitral é feito para permitir, coada, a entrada da luz do sol, o seu motivo maior.

Resgato, agora e para finalizar, nossa proposta de gestão, a fim de reafirmar o compromisso de Campinas e o nosso desejo de compartilhá-la 
com todos os colegas da área que nos deram a necessária força para chegar até aqui.

Para além de atender às finalidades e aos objetivos já definidos no Estatuto da $\Lambda$ NPOLL, a direção hoje empossada pretende desenvolver três grandes linhas de ação: política, acadêmica e de organização interna.

1. Quanto às ações políticas, são nossos objetivos:

- consolidar a atuação da NNPOLL junto aos órgãos federais e estaduais de fomento à pesquisa (CNPq, CAPES, FINEP e FAPs), no sentido de intervir de forma mais direta na definição de políticas para a área;

- estabelecer um foro permanente de debates com outras associações da área ( $\Lambda \mathrm{BR} \Lambda \mathrm{LIC}, \Lambda \mathrm{BR} \Lambda \mathrm{LIN}$, por exemplo) e de áreas afins (como $\Lambda$ NPOCS e $\Lambda$ NPED), no sentido de fazer frente à política de esvaziamento que vêm sofrendo as áreas das ciências humanas e sociais, pouco valorizadas no atual modelo de desenvolvimento de ciência e tecnologia praticado no país. $\Lambda$ partir de uma ampla discussão sobre os grandes problemas comuns, buscaremos organizar ações conjuntas que possam devolver prestígio e relevância à produção científica, em nosso caso particular, da área de Letras e Lingüística, conferindo-lhe visibilidade pública.

2. No que diz respeito às ações de natureza acadêmica, objetivamos:

- coletar informações sobre linhas de pesquisa, produção científica, atividades acadêmicas e eventos promovidos pelos Programas de Pós-graduação, informações estas que venham a atualizar os dados já disponíveis nas agências de fomento e na publicação Quem é quem, a fim de analisá-los e estabelecer uma espécie de radiografia do estágio atual da pesquisa em nível de pós-graduação. Linda com base nesses dados, propor um novo desenho para as subáreas configuradas pelas agências de fomento, que esteja mais de acordo com o que concretamente se tem feito na pesquisa em Letras e Lingüística; 
PADILHA, Laura Cavalcante. Discurso de posse.

- apoiar eventos científicos realizados pelos diversos Cursos de Pós-graduação, encontrando formas de difundir sua programação e, posteriormente, os resultados alcançados, por via eletrônica ou pelo Informativo ANPOLL;

- estimular a utilização pelos GTs da Home Page da $\Lambda$ NPOLL, a fim de que o pensamento científico neles gerado se possa difundir nacional e internacionalmente.

3. Por fim, com relação à questão da organização interna, pretendemos envidar esforços para:

- garantir a realização dos Encontros periódicos da $\Lambda$ NPOLL, dando continuidade ao que historicamente se vem fazendo desde a sua criação;

- manter a periodicidade e ampliar a distribuição da Revista da ANPOLL;

- constituir uma memória dos Cursos, que deverá ser continuamente realimentada: grupos e linhas de pesquisa, estrutura curricular, eventos anualmente programados, vinda de professores visitantes, com um intercâmbio em nível nacional e internacional, institutos de verão etc.;

- apoiar a atualização dos dados do Quem é quem em Letras e Lingüística, assegurando-lhe a periodicidade anual;

- manter aberto o canal de comunicação entre os Coordenadores de GTs e a Diretoria da $\Lambda$ NPOLL, de modo a facilitar e valorizar as ações por eles desenvolvidas;

- estimular, junto aos Programas que sediam a Coordenação dos GTs, um efetivo apoio institucional que lhes garanta a execução das metas e tarefas específicas;

- criar um cadastro de professores aposentados de reconhecida produção científica, para que os Programas se possam beneficiar de sua experiência e trabalho acadêmico.

Espera-se que o conjunto dessas ações resulte no fortalecimento do perfil político-acadêmico e no alargamento do âmbito de atuação da $\Lambda$ NPOLL, de modo a que ela seja investida de maior poder de chancela e 
Rev. $A N P(L L L$, n. 6/7, p. 315-323, jan./dez. 1999

aval junto à comunidade acadêmico-científica da área de Letras e Lingüística no País.

Para concluir, gostaria de lembrar os versos de Sérgio Magrão e Luiz Carlos Sá, inesquecíveis na voz de Milton Nascimento:

\author{
"Nada a temer \\ Senão o correr da luta \\ Nada a fazer \\ Senão esquecer o medo \\ Abrir o peito à força \\ Numa procura \\ Fugir às armadilhas da mata escura \\ Longe se vai sonhando demais..."
}

Que o sonho siga sempre como nosso companheiro, sem que tenhamos medo de ser felizes.

Obrigada. 